\title{
LncRNA regulates tomato fruit cracking by coordinating gene expression via a hormone-redox-cell wall network
}

\author{
Lingzi Xue ${ }^{1,2}$, Mintao Sun ${ }^{3}$, Zhen $\mathrm{Wu}^{1,2}$, Lu Yu ${ }^{1,2}$, Qinghui $\mathrm{Yu}^{4}$, Yaping Tang ${ }^{4}$ and Fangling Jiang ${ }^{1,2^{*}}$
}

\begin{abstract}
Background: Fruit cracking occurs easily under unsuitable environmental conditions and is one of the main types of damage that occurs in fruit production. It is widely accepted that plants have developed defence mechanisms and regulatory networks that respond to abiotic stress, which involves perceiving, integrating and responding to stress signals by modulating the expression of related genes. Fruit cracking is also a physiological disease caused by abiotic stress. It has been reported that a single or several genes may regulate fruit cracking. However, almost none of these reports have involved cracking regulatory networks.

Results: Here, RNA expression in $0 \mathrm{~h}, 8 \mathrm{~h}$ and $30 \mathrm{~h}$ saturated irrigation-treated fruits from two contrasting tomato genotypes, 'LA1698' (cracking-resistant, CR) and 'LA2683' (cracking-susceptible, CS), was analysed by mRNA and IncRNA sequencing. The GO pathways of the differentially expressed mRNAs were mainly enriched in the 'hormone metabolic process', 'cell wall organization', 'oxidoreductase activity' and 'catalytic activity' categories. According to the gene expression analysis, significantly differentially expressed genes included Solyc02g080530.3 (Peroxide, POD), Solyc01g008710.3 (Mannan endo-1,4-beta-mannosidase, MAN), Solyc08g077910.3 (Expanded, EXP), Solyc09g075330.3 (Pectinesterase, PE), Solyc07g055990.3 (Xyloglucan endotransglucosylase-hydrolase 7, XTH7), Solyc12g011030.2 (Xyloglucan endotransglucosylase-hydrolase 9, XTH9), Solyc10g080210.2 (Polygalacturonase-2, PG2), Solyc08g081010.2 (Gamma-glutamylcysteine synthetase, gamma-GCS), Solyc09g008720.2 (Ethylene receptor, ER), Solyc11g042560.2 (Ethylene-responsive transcription factor 4, ERF4) etc. In addition, the IncRNAs (XLOC_16662 and XLOC_033910, etc) regulated the expression of their neighbouring genes, and genes related to tomato cracking were selected to construct a IncRNA-mRNA network influencing tomato cracking.

Conclusions: This study provides insight into the responsive network for water-induced cracking in tomato fruit. Specifically, IncRNAs regulate the hormone-redox-cell wall network, including plant hormone (auxin, ethylene) and ROS $\left(\mathrm{H}_{2} \mathrm{O}_{2}\right)$ signal transduction and many cell wall-related mRNAs (EXP, PG, XTH), as well as some IncRNAs (XLOC_ 16662 and XLOC_033910, etc.).
\end{abstract}

Keywords: Tomato, LncRNA, mRNA, Transcriptome, Network, Fruit cracking

\footnotetext{
* Correspondence: jfl@njau.edu.cn

${ }^{1}$ College of Horticulture, Nanjing Agricultural University, Weigang NO 1, Nanjing 210095, Xuanwu District, China

${ }^{2}$ Key Laboratory of Horticultural Plant Biology and Germplasm Innovation in East China, Ministry of Agriculture, Nanjing 210095, China

Full list of author information is available at the end of the article
}

(C) The Author(s). 2020 Open Access This article is licensed under a Creative Commons Attribution 4.0 International License, which permits use, sharing, adaptation, distribution and reproduction in any medium or format, as long as you give appropriate credit to the original author(s) and the source, provide a link to the Creative Commons licence, and indicate if changes were made. The images or other third party material in this article are included in the article's Creative Commons licence, unless indicated otherwise in a credit line to the material. If material is not included in the article's Creative Commons licence and your intended use is not permitted by statutory regulation or exceeds the permitted use, you will need to obtain permission directly from the copyright holder. To view a copy of this licence, visit http://creativecommons.org/licenses/by/4.0/ The Creative Commons Public Domain Dedication waiver (http://creativecommons.org/publicdomain/zero/1.0/) applies to the data made available in this article, unless otherwise stated in a credit line to the data. 


\section{Background}

Fruit cracking, one of the main disorders in fruit production, can easily cause adverse impacts in fruit marketability such as reducing fruit quality due to a poor appearance, decreasing shelf life, and even making the fruit unmarketable because of fungal infection [1].

Fruit cracking occurs easily under unsuitable environmental conditions. For instance, under abiotic stress caused by dry to very wet conditions, there will be a rapid flow into the fruit, and if the skin loses strength and elasticity due to factors such as maturation, cracking is most likely to occur [2]. It is widely accepted that plants have developed defence mechanisms and regulatory networks to respond to abiotic stress, which involve perceiving, integrating and responding to stress signals by modulating the expression of related genes [3-8]. Fruit cracking is also a kind of physiological disease caused by abiotic stress. Is there a regulatory network involved in fruit cracking?

Since the 1930s, researchers have performed many theoretical and practical studies on cracking $[2,9,10]$. Cracking is the result of a combination of internal and external factors. The internal factors are the fruit's own characteristics (fruit size, shape, firmness, deposition of cutin, wax, strength of the pericarp, arrangement of cells in the pericarp, quantity and status of stomata, accumulation of osmoregulatory substances such as soluble sugars, growth stage of the fruit, etc.), while the external factors mainly include environmental factors (humidity, light, temperature, wind, etc.) and cultivation management measures (irrigation, mineral nutrition, plant regulation, etc.) [10-13]. Cortes [14] comprehensively analysed 62 genotypes and found that the correlation of cracked fruit with heredity was significantly greater than that with the environment, indicating that the cracking characteristic can show stable heritability and be regulated by certain genes.

Notably, cell wall components and modifications appear to be correlated with the strength of the skin and fruit cracking [15-18]. As ripening proceeds, cell wall degradation gradually occurs, and the fruit cracking rate increases $[15,16]$. The cell wall is composed of a cellulose-hemicellulose (Cel-Hem) network and pectin, which is essential to maintain the mechanical strength of the cell wall. As the fruit matures, enzymes and proteins that degrade the polysaccharide components of the cell wall are produced, such as polygalacturonase (PG), extended protein $(E X P)$, pectin methylesterase (PME), pectate lyases (PL), pectinase, $\beta$-galactosidase. ( $\beta$-gal) and cellulase $(C x)$ [19-22]. The synergistic action of these enzymes leads to the degradation of cell wall polysaccharides and softening of the mature fruit peel [23]. Previous research has shown that genes such as EXP, PG, $\beta$ gal and XET are associated with fruit cracking [24-29]. Inhibition of $\beta$-gal gene expression increases the rate of fruit cracking [27]. In tomato, inhibition of LePG expression slightly reduces the rate of fruit cracking [28]. Simultaneous suppression of SIPG and SIEXP1 expression in ripening fruits reduces cell wall disassembly and thereby reduces the fruit cracking rate by approximately $12 \%$ [30]. It is not a single gene but many genes working together that regulate fruit cracking [30-33]. It remains unclear whether there are other genes related to fruit cracking and which one is the major gene.

NcRNAs (Non-coding RNA) are involved in a lot of life processes, such as cell growth, differentiation, proliferation, and apoptosis [34-38]. In contrast to the approximately $2 \%$ of protein-coding genes, more than $90 \%$ of genes do not have the ability to encode proteins and are transcribed into ncRNAs [34]. These ncRNAs were originally thought to represent "expression noise" or "expression waste", but they have now been proven to be strictly regulated to play important roles in the biological processes of organisms and exhibit extremely complex biological functions [36-38]. While much of the published work on ncRNAs has been conducted in humans and animals, the studies on plants are limited to certain model plants, such as Arabidopsis, maize, and wheat [39, 40]. Xin [39] identified 125 stress-related lncRNAs (long non-coding RNA) in wheat, among which 71 responded to powdery mildew, and 77 responded to heat stress. Swiezewski [40] discovered that cold-induced long antisense intragenic RNA (COOLAIR) is involved in the vernalization process and regulates the expression of the plant flowering suppressor "gene flowering locus C" $(F L C)$. Wang [41] reported the expression and evolution of lncRNAs in Solanaceae. Cui's [42] results provided insights into the WRKY1 - lncRNA33732 - RBOH module involved in the regulation of $\mathrm{H}_{2} \mathrm{O}_{2}$ accumulation and resistance to pathogens in tomato. Wang [43] identified several $\ln R N A s$ that are involved in TYLCV infection by virus-induced gene silencing (VIGS) and genome-wide analysis. However, none of these studies have focused on lncRNAs and fruit cracking. Is it possible that lncRNAs play important roles in fruit cracking too?

This study aimed to obtain a global view of the transcriptional regulation (mRNAs and lncRNAs) of fruit cracking induced by irrigation in tomato. Differentially expressed mRNAs and lncRNAs related to fruit cracking were identified through transcriptome profiling and bioinformatic analysis. Finally, we determined a lncRNAregulated hormone-redox-cell wall network for waterinduced cracking in tomato. The findings reported here can increase our understanding of the transcriptional regulatory mechanisms of fruit cracking.

\section{Results}

RNA sequencing and identification of IncRNA and mRNA

In total, we obtained 0.81 to 1.14 billion raw reads and 0.79 to 1.14 billion clean reads from $\mathrm{CR}$ and CS tomatoes at 
Table 1 The overall assessment of the sequencing data

\begin{tabular}{lllllllll}
\hline Sample_name & Raw_reads & Clean_reads & Raw_bases(G) & Clean_bases(G) & Error rate(\%) & Q20(\%) & Q30(\%) & GC_content(\%) \\
\hline CR_0h_1 & $102,656,082$ & $102,656,082$ & 15.4 & 15.4 & 0.01 & 98.13 & 95.03 & 42.82 \\
CR_30h_1 & $80,567,758$ & $80,567,758$ & 12.09 & 12.09 & 0.02 & 96.32 & 91.05 & 42.29 \\
CR_8h_1 & $79,478,876$ & $79,478,876$ & 11.92 & 11.92 & 0.02 & 96.41 & 91.23 & 42.94 \\
CR_0h_2 & $97,730,610$ & $97,730,610$ & 14.66 & 14.66 & 0.01 & 97.99 & 94.69 & 42.52 \\
CR_30h_2 & $100,192,938$ & $100,192,938$ & 15.03 & 15.03 & 0.01 & 97.98 & 94.69 & 42.44 \\
CR_8h_2 & $94,324,174$ & $94,324,174$ & 14.15 & 14.15 & 0.01 & 98.1 & 94.97 & 42.77 \\
CS_0h_1 & $95,783,116$ & $95,783,116$ & 14.37 & 14.37 & 0.01 & 97.58 & 93.81 & 42.95 \\
CS_30h_1 & $90,916,088$ & $90,916,088$ & 13.64 & 13.64 & 0.02 & 96.86 & 92.29 & 42.84 \\
CS_8h_1 & $86,534,460$ & $86,534,460$ & 12.98 & 12.98 & 0.01 & 97.79 & 94.28 & 42.96 \\
CS_0h_2 & $103,713,024$ & $103,713,024$ & 15.56 & 15.56 & 0.01 & 98.02 & 94.78 & 42.79 \\
CS_30h_2 & $98,559,578$ & $98,559,578$ & 14.78 & 14.78 & 0.01 & 97.97 & 94.71 & 42.39 \\
CS_8h_2 & $114,298,442$ & $114,298,442$ & 17.14 & 17.14 & 0.01 & 97.89 & 94.49 & 43 \\
\hline
\end{tabular}

various time points $(0 \mathrm{~h}, 8 \mathrm{~h}$ and $30 \mathrm{~h}$ of saturated irrigation treatment) (Table 1). Through genomic comparison, Cufflinks splicing, and CPC2 and PFAM analysis, we identified 1 annotated lncRNA, 2508 putative lncRNAs, 33,784 annotated mRNAs and 409 novel mRNAs (Additional file 1).

\section{Feature analysis of IncRNAs and identification of IncRNA- mRNA pairs}

The average length of the obtained lncRNAs was 1470 $\mathrm{nt}$, which was similar to that of the mRNAs (1221 nt); the average number of exons and average ORF length of the identified lncRNAs were 2.6 and $88.5 \mathrm{bp}$, which were much lower values than those for the mRNAs (4.7 and $347 \mathrm{bp}$ ) (Fig. 1), consistent with previous studies [44, 45]. At the same time, we used phyloP to separately score the lncRNAs and mRNAs, and the sequence conservation of the lncRNAs was lower than that of mRNAs, which was consistent with previous studies [46]. We identified 21,048 lncRNA-mRNA pairs with target relationships upstream and downstream of 2508 lncRNAs (Additional file 2).

\section{Differential expression analysis}

Differentially expressed mRNAs and lncRNAs were analysed in CR and CS tomatoes by using edge R software (Fig. 2) and the number of differentially expressed genes was listed in the Additional file 3. mRNAs and lncRNAs with a $Q$-value $<0.05$ and $\mid \log 2$ fold-change $\mid>1$ were selected as differentially expressed genes.

\section{Functional prediction of DEGs}

To investigate the trends in gene functions and enrichment for DEGs, we performed GO (Gene Ontology) analysis of the selected mRNAs (Fig. 3; Additional file 4). The results showed that DEGs in the CR tomato were involved in a series of biological processes, such as regulation of biological process, biological regulation and regulation of cellular process, as well as catalytic activity.

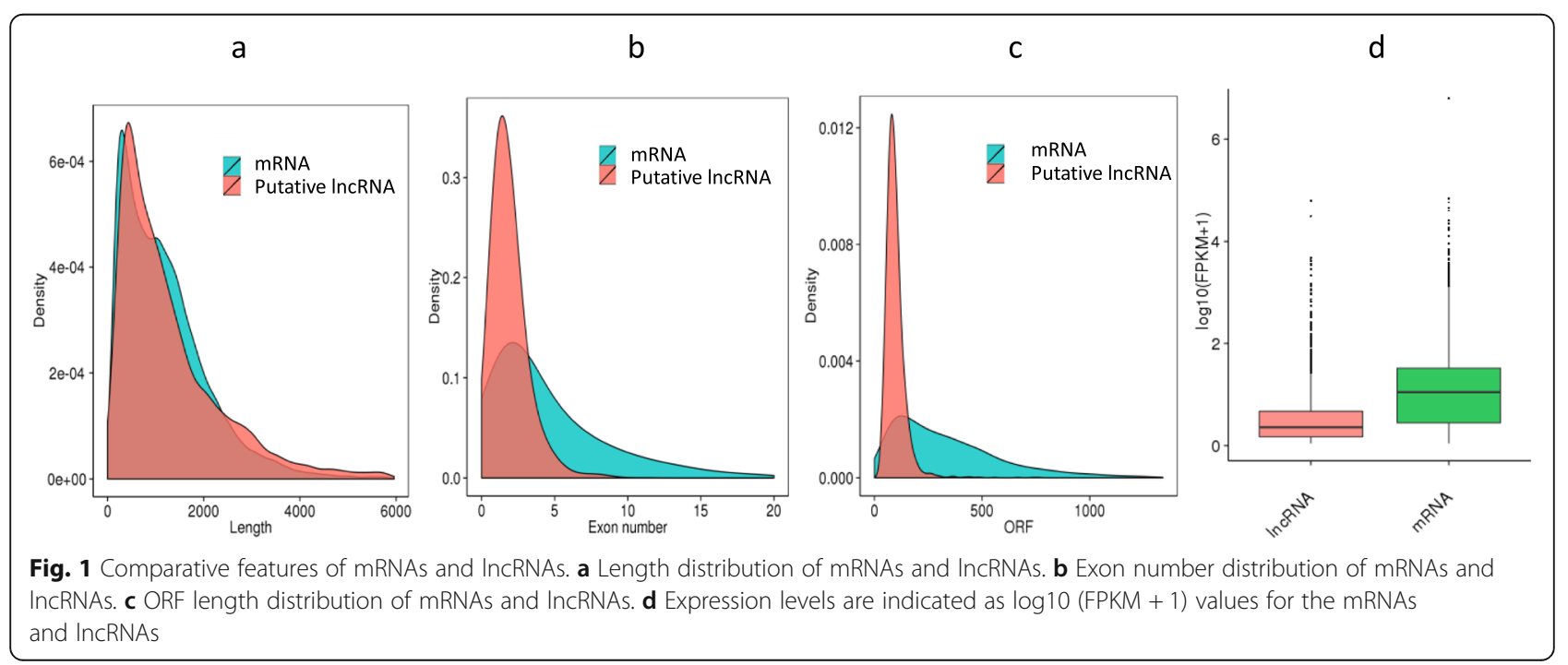



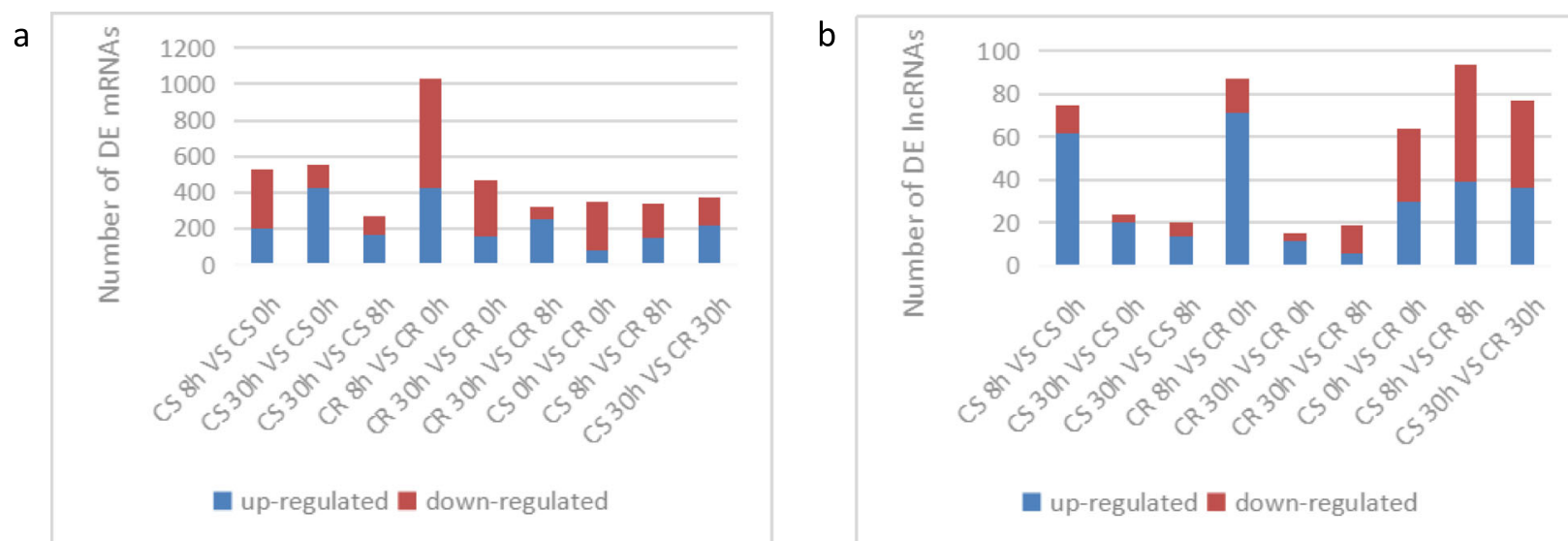

Fig. 2 Differentially expressed mRNAs and IncRNAs in different libraries. Upregulated (blue) and downregulated (red) mRNAs and IncRNAs were quantified. a mRNAs. b IncRNAs. Note: CS is cracking-susceptible, CR is cracking-resistant. The same abbreviations are used below

For the CS tomato, DEGs were mainly involved in single-organism metabolic process, biological process and catalytic activity. Between the CR and CS tomatoes, before irrigation treatment $(0 \mathrm{~h})$, DEGs were significantly enriched in oxidoreductase activity; after $8 \mathrm{~h}$ of irrigation treatment, there were some DEGs enriched in fruit ripening, anatomical structure maturation, and ageing; after $30 \mathrm{~h}$ of irrigation treatment, the number of DEGs enriched in the catalytic category was the highest, followed by the single-organism metabolic process and oxidation-reduction process categories, and cell components.

To better understand the function of the DEGs, significantly enriched KEGG pathways were analysed (Fig. 4; Additional file 5). The results showed that the DEGs were mainly enriched in the 'biosynthesis of secondary metabolites', 'cysteine and methionine metabolism', 'metabolic pathways', 'plant-pathogen interaction', 'photosynthesisantenna protein', 'photosynthesis', 'histidine metabolism' and 'circadian rhythm-plant' categories.

\section{DEGs (cell wall, redox, hormone related) regulate tomato fruit cracking}

According to the gene expression analysis, 16 significantly differentially expressed genes (Additional file 6) were predicted to be related to fruit cracking in tomato, such as Solyc02g080530.3 (Peroxide, POD), Solyc01g008710.3 (Mannan endo-1,4-beta-mannosidase, MAN), Solyc08g077910.3 (Expanded, EXP), Solyc09g075330.3 (Pectinesterase, PE), Solyc07g055990.3 (Xyloglucan endotransglucosylasehydrolase 7, XTH7), Solyc12g011030.2 (Xyloglucan endotransglucosylase-hydrolase 9, XTH9), Solyc10g080210.2 (Polygalacturonase-2, PG2), Solyc08g081010.2 (Gamma-glutamylcysteine synthetase, gamma-GCS), Solyc09g008720.2 (Ethylene receptor, ER), Solyc11g042560.2 (Ethylene-responsive transcription factor 4, ERF4) etc. (Table. 2 [47-70]).
Hierarchical clustering analysis showed that the expression trends or levels of these genes in the two varieties were completely different after the irrigation treatment (Fig. 5a). For instance, the expression of $X T H 7, X T H 9, P E$ and $P O D$ in the CR tomato showed a downward trend, while the expression in the CS tomato presented an upward trend. These genes play important roles in cell wall loosing and expansion. As disassembly of the fruit cell wall can influence fruit cracking [30], These plant cell-wall loosing genes may also play a key regulatory role in tomato fruit cracking. At the same time, we used Tomato Gene Expression Atlas (http://tea.solgenomics.net/expression_viewer/input) to verify the gene expression, and found that most differentially expressed genes in this experiment were expressed in tomato pericarp in red ripe stage. Among them, GCS, MAN and PG, the antioxidative genes and cell-wall degrading enzyme-associated genes showed the highest expression. Whereas high mRNA levels were never present in $E R F$. These might be because that the $E R F$ is an upstream regulator [71], so it never presented a high expression in red ripe stage. The differences in gene expression in this experiment and Tomato Gene Expression Atlas might be due to different varieties, treatment and detection standards (Fig. 5b).

Finally, we mapped a pathway diagram (Fig. 5c) of fruit cracking based on these differentially expressed IncRNAs, mRNAs and previous studies [71-77]. Within this pathway, ERF, $P O D, P G$ and $P E$ play important roles. Previous researches suggests that ethylene influences fruit development and ripening (regulating cell wall-related $P G$ and EXP gene expression) [71] and promotes programmed cell death of epithelial cells under ROS signalling [72]. Li et al. [73] showed that ARFs represent a point of cross-talk between ethylene and auxin signalling. Furthermore, auxin induces the production of ROS, and $\mathrm{H}_{2} \mathrm{O}_{2}$ decomposes polymers at the cell wall by producing $\cdot \mathrm{OH}$ [74]. Programmed cell death leads to a 


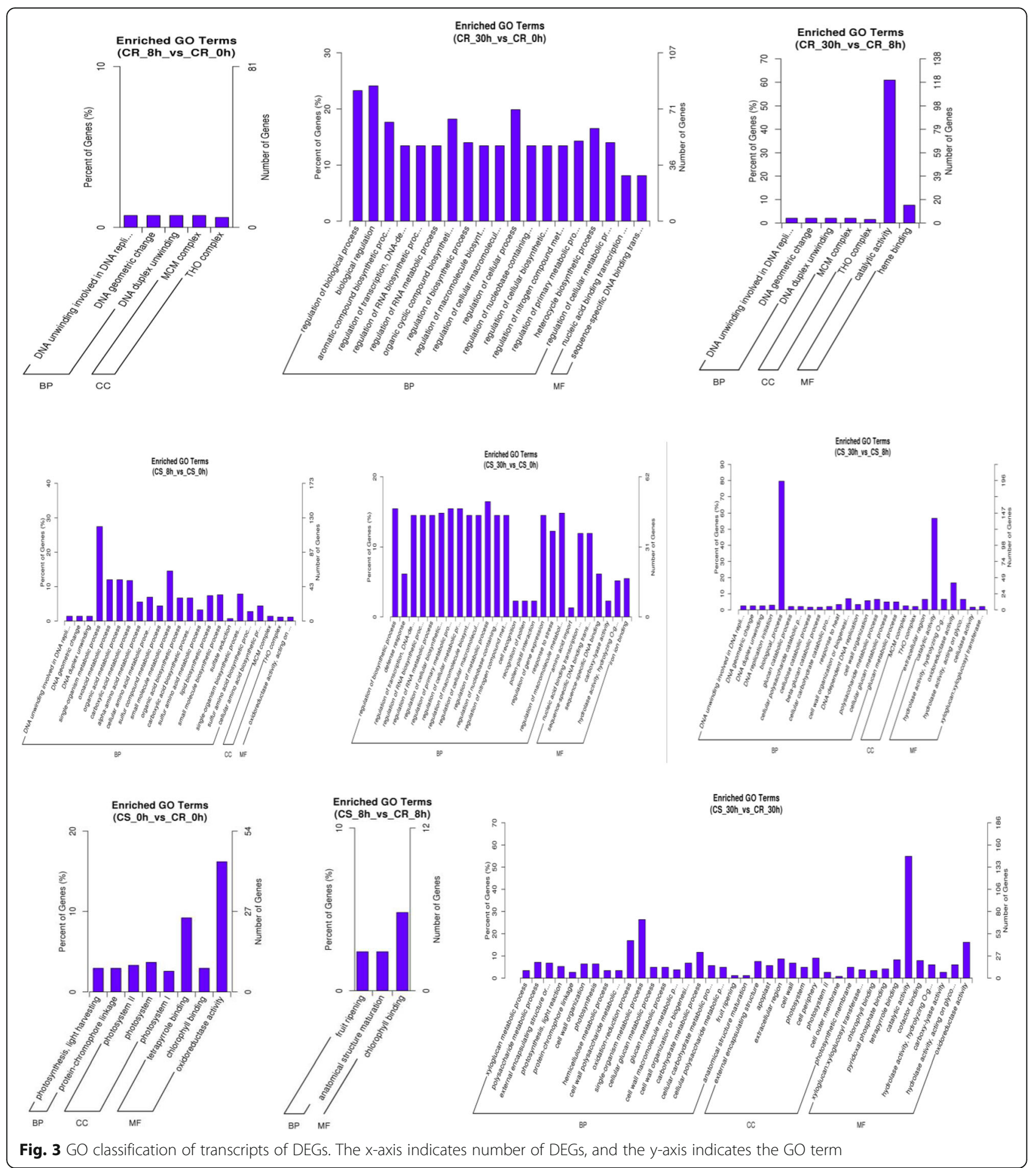

reduction in or loss of permeability of the plasma membrane, which in turn influences fruit cell activity, water absorption and cracking [75]. Simultaneously, the increase of auxin can promote the accumulation of $\mathrm{H}_{2} \mathrm{O}_{2}$ and the elongation of cells [76]. Furthermore, Rayle and Cleland [77] proposed the acid growth theory indicating that hydrogen ions may exert a purely chemical or physical effect, such as cleavage of acid-labile bonds on the wall, or they may activate normal enzymatic processes directly or indirectly, potentially leading to wall loosening. We analyzed the regulatory element in the promoter sequence of $P G, P E, E X P$ and $X T H 7$ and found that there are Ethylene-responsive element and auxinresponsive element. Based on these findings, we 


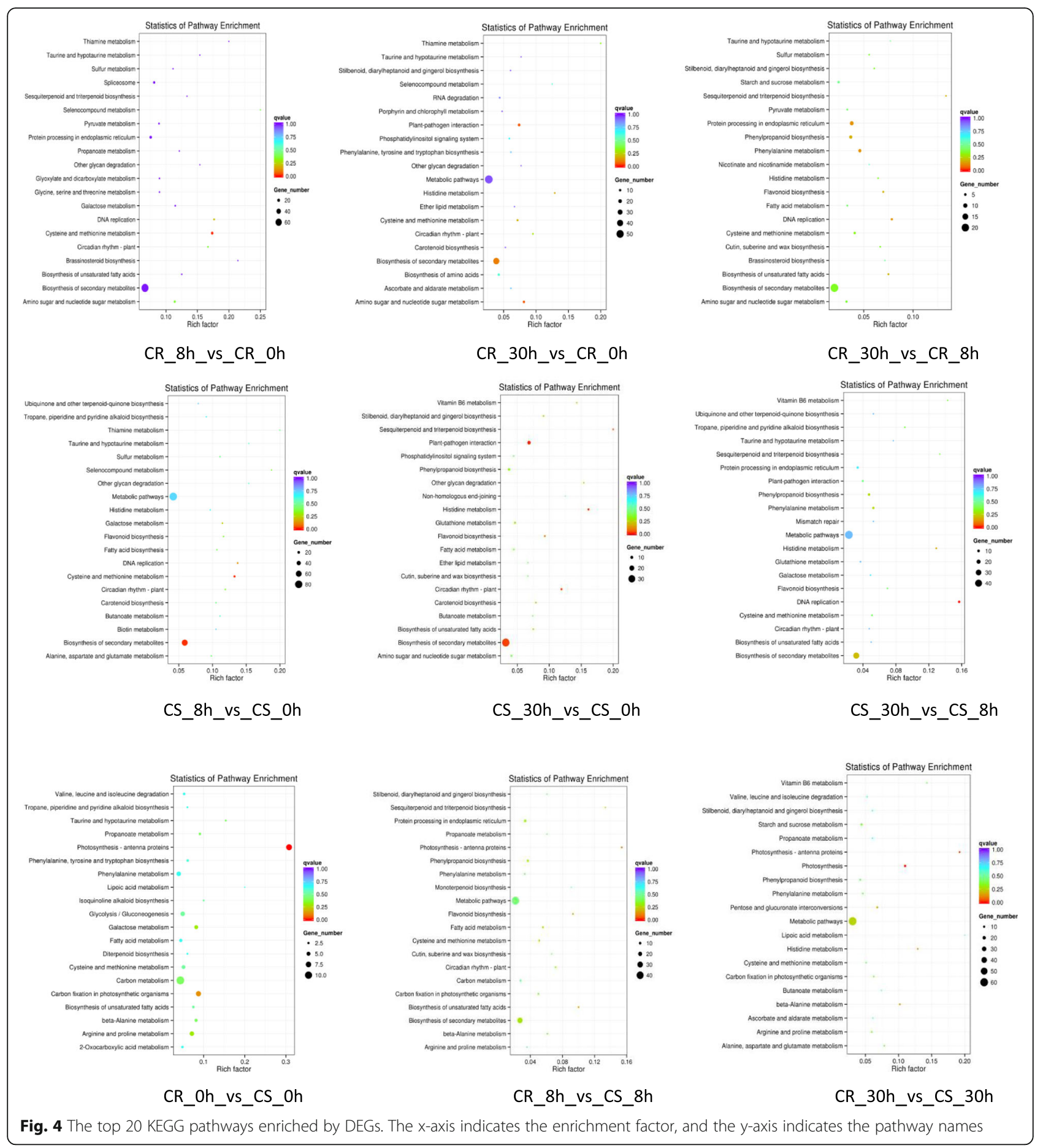

speculate that the regulatory network of fruit cracking, especially the coexpression of cell wall-, redox-, and hormone-related mRNAs and their corresponding lncRNAs, influences fruit cracking.

\section{qRT-PCR validation of DEGs}

Genes showing upregulated and the downregulated expression were randomly selected from the DEGs for
qRT-PCR verification. The results of qRT-PCR revealed that most of these mRNAs shared similar expression tendencies to those indicated by the mRNA-Seq data, which can validate the reliability of our sequence data and our research results from the present study (Additional file 7). The expression levels detected by the two methods were slightly different, which might have been due to the different detection ranges and sensitivities of 
Table 2 Key genes related to tomato fruit cracking

\begin{tabular}{lll}
\hline Gene ID & Gene Function & Previous Studies \\
\hline Solyc07g055990.3 & xyloglucan endotransglucosylase-hydrolase 7 & Park Y B [47] \\
Solyc12g011030.2 & xyloglucan endotransglucosylase-hydrolase 9 & Jan A [48] \\
Solyc01g081060.2 & xyloglucan endotransglucosylase-hydrolase 14 (XTH 7, XTH 9, XTH 14) & He H [49] \\
Solyc10g080210.2 & Polygalacturonase-2 (PG 2) & Tieman DM [50] \\
Solyc09g075330.3 & Pectinesterase (PE) & Quesada MA [51] \\
Solyc08g077910.3 & Expanded protein (EXP) & McQueen-Mason S [52] \\
Solyc01g008710.3 & Mannan endo-1,4-beta-mannosidase (MAN) & Mo B [53] \\
& & Stålbrand H [54] \\
Solyc02g080530.3 & Peroxide (POD) & Mohammad I [55] \\
& & Andrews J [56] \\
& & Cordoba-Pedregosa C [57] \\
Solyc01g081250.3 & Lin CC [58] \\
Solyc08g081010.3 & Glutathione-S-transferase (GST) & Passardi F [59] \\
& Gamma-glutamylcysteine synthetase (gamma-GCS) & Jablonkai I [60] \\
Solyc09g008720.2 & & Kampranis SC [60] \\
Solyc11g042560.2 & Ethylene receptor (ER) & Marrs KA [61] \\
& Ethylene-responsive transcription factor (ERF4) & Bartling D [62] \\
& & Trainotti L [63] \\
& & Ruther J [64] \\
& & Hossain MA [65] \\
Jeong SW [66]
\end{tabular}

the two detection methods. The comparison of the relative expression measured by qRT-PCR and RNA-seq was showed in Additional file $8, R^{2}>0.7$ confirmed the reliability of the RNA-Seq analysis results.

\section{Discussion}

Tomato is one of the most popular commercial vegetables [78], however, its fruit shows high susceptibility to cracking $[16,31]$. Cracks can occur throughout the fruit development stage during the ripening and post-harvest period [79, 80], which may cause serious economic losses. Different hypotheses have been presented to explain the occurrence of tomato fruit cracking. Previous studies have shown that rapid fruit swelling and fruit cracking are closely related [81]. Irregular temperatures or watering, especially a shift from a lower temperature to a much higher temperature or from extremely dry to very humid conditions, will lead to rapid swelling. The pressure of the rapidly expanding pulp on the peel may lead to fruit cracking [82]. Cell senescence and apoptosis also influence skin strength and water absorption, which can in turn affect fruit cracking [10]. In addition, a large differences between day and night temperatures can lead to the accumulation of carbohydrates [83]. Fruits with high levels of carbohydrates absorb more water, grow much faster and are more likely to crack [84]. In general, fruit cracking is a complex problem involving a mixture of genetics and the environment. Previous studies have suggested it is not a single gene but many genes that work together to regulate fruit cracking [31, 32].

\section{Cell wall polysaccharide metabolic}

The DEG Solyc08g077910.3 encodes an Expansin-like protein that breaks down the hydrogen bonds between molecules in the cell wall macromolecular network to promote the depolymerization of the network, which can lead to relaxation of the cell wall [52]. In this experiment, the expression level of Solyc08g077910.3 was increased significantly after $8 \mathrm{~h}$ of irrigation ( $\log 2$ foldchange $=7.13395)$ in CS tomato. The increased expression of the expansin-like gene can relax the cell wall and may influence fruit cracking.

Solyc07g055990.3 and Solyc12g011030.2 encode xyloglucan endotransglucosylase/hydrolases 7 and 9, respectively, which mediate the cleavage and polymerization of $\beta-1,4$-xyloglucan in the primary cell wall. Xyloglucan is usually fused to the cell wall, and its oligosaccharides determine tissue tension [47]. Jan [48] found that OsXTH8 is involved in the cell wall modification process in rice and is highly expressed in the vascular bundle of the sheath and the young roots, in which the cells are rapidly elongated and differentiated. In addition, it can respond to gibberellin. He [49] found that OsXTH5, OsXTH19, OsXTH20, OsXTH24 and OsXTH28 play important roles in the elongation of rice peduncles and can respond to drought stress. These studies indicate that the OsXTH gene family plays an important role in the regulation of the structural function of rice cell walls. In this experiment, the expression levels of Solyc12g011030.2 and Solyc07g055990.3 in CS tomato showed an upward trend, while they showed a downward trend in the CR 

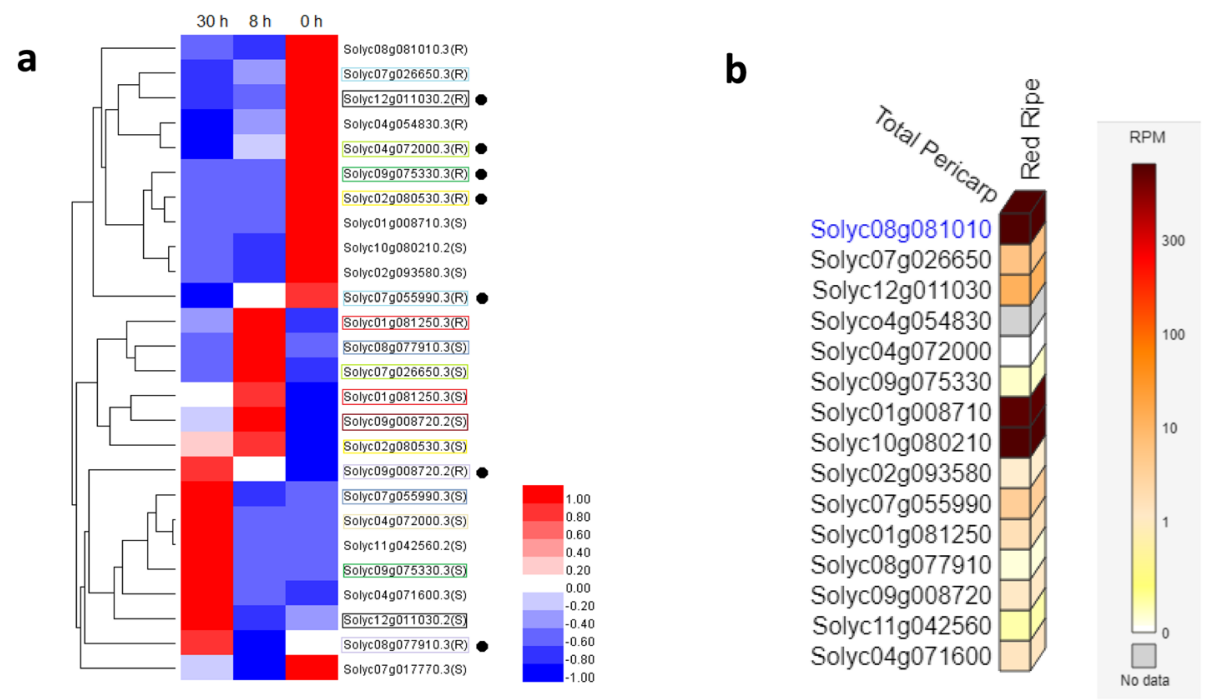

C

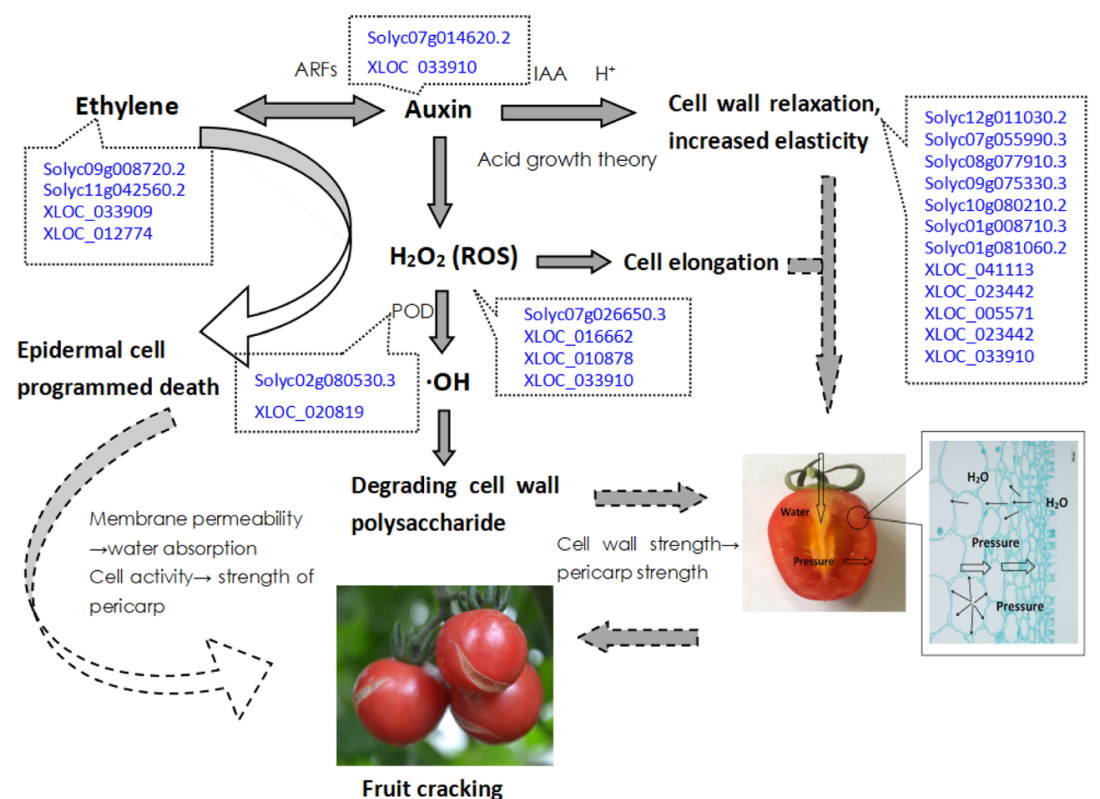

Fig. 5 Hierarchical clustering analysis and proposed fruit cracking regulatory network. a Hierarchical clustering analysis showed the expression profiles of key genes involved in tomato fruit cracking. Based on the Euclidean distance, the minimum linkage method was used for cluster analysis. Boxes of the same colour represent the same gene in CS and CR. The solid dark circles represent genes that showed different expression trends in the two genotypes. $\mathbf{b}$ Gene expression cube in total pericarp of tomato during red ripen stage by using Tomato Gene Expression Atlas. c Predicted pathway diagram of fruit cracking in tomato, including hormones, reactive oxygen species, and cell wall polysaccharide metabolism. Solyc09g008720.2, ethylene receptor. Solyc1 1g042560.2, ethylene-responsive transcription factor. Solyc02g080530.3, peroxide. Solyc07g026650.3, 1aminocyclopropane-1-carboxylate oxidase 5. Solyc07g055990.3, xyloglucan endotransglucosylase/ hydrolase 7. Solyc12g011030.3, xyloglucan endotransglucosylase/ hydrolase 9. Solyc08g077910.3, expansin. Solyc09g075330.3, pectinase. Solyc10g080210.2, polygalacturonase-2. Solyc09g075330.3, pectinesterase. XLOC_016662, XLOC_010878 and XLOC_033910 are predicted IncRNAs associated with the redox pathway. The dotted line indicates the speculation process

tomato (Fig. 5a). Simultaneously, the expression level in CS tomato was significantly higher than that in CR tomato. This illustrates that the CR tomato may exhibit a greater osmotic stress resistance ability with downregulation of the $X T H$ gene that can strengthen the cell wall upon encountering water stress.
The DEG Solyc10g080210.2 (Polygalacturonase-2) can remove the methyl group from polygalacturonic acid; during tomato maturation, the degree of methylation decreases from $90 \%$ in the green ripen period to $35 \%$ in the red ripen period [50], which accelerates the degradation of the cell wall. In an antisense PaPG1 transgenic 
study of strawberry, the expression level of $P G$ was significantly inhibited, and the degree of fruit softening was significantly delayed [51].

\section{Redox processes}

Previous studies have shown that peroxidase in the cell wall leads to cell wall sclerosis by causing cross-linking of cell wall components, thereby inhibiting cell elongation [56-58]. Peroxidase can also directly regulate plant cell elongation by controlling $\mathrm{H}_{2} \mathrm{O}_{2}$ levels [59]. Solyc02g080530.3 encodes peroxide, whose levels are significantly higher in CS tomato than in CR tomato. The expression of these genes in CS tomato fruits may increase cell wall hardness and hinder the elongation of the cell wall, which will lead to fruit cracking when water absorption swelling occurs. Solyc01g081250.3 encodes glutathione-S-transferase (GST). The GST superfamily enzymes exhibit multiple functions in plants. They are not only involved in primary metabolism and secondary metabolism [70], but they can also protect plants from oxidative damage and heterogeneous substances [60-62]. According to the data analysis, the gene expression of Solyc01g081250.3 in the CR tomato was significantly higher than that in the CS tomato after $0 \mathrm{~h}$, $8 \mathrm{~h}$ and $30 \mathrm{~h}$ of irrigation treatment. Higher expression of GST in CR tomato can better maintain cell vigour and be beneficial to tomato fruits when coupled with water stress.

\section{Hormone-related}

Previous research has shown that hormones can regulate the expression of cell wall-related genes. Trainotti [63] studied the expression of 32 genes related to cell wall synthesis and degradation. Their research showed that the expression of these genes in fleshy fruits can be inhibited by ethylene, while ethylene promotes the expression of these genes during fruit ripening and softening. At the same time, ethylene inhibits and promotes dual regulatory effects on the formation of plant secondary metabolites [64-66]; TAPG1, encoding a cell walldegrading enzyme, can be induced by ethylene at the transcriptional level in tomato [67]; Rose [68] showed

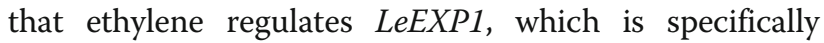
expressed only during fruit ripening. The pathway of ethylene biosynthesis in plants is the methionine cycle [85-87]. In this study, KEGG functional analysis of DEGs revealed significant enrichment in the methionine metabolic pathway. Solyc11g042560.2 encodes an ethylene receptor, while Solyc09g008720.2 encodes an ethylene-responsive transcription factor, and their expression levels are significantly upregulated after irrigation and are higher in CS tomato than in CR tomato.

\section{LncRNAs regulate tomato fruit cracking by coordinating} gene expression in the hormone-redox-cell wall network Liu's research suggests that plants have gradually developed complex signalling pathways to cope with adverse environmental stimuli [8]. That is, plants perceive different stress signals from the circumstances in which they occur and then integrate these signals and respond to these different stresses by modulating the expression of related genes. Is it possible that cracking is also regulated by a complex network?

LncRNAs play important roles in epigenetic regulation, cell cycle regulation and many other activities. Here, we identified several lncRNAs that are involved in fruit cracking. Most lncRNAs are not annotated, and we do not know their functions. To predict the functions of these lncRNAs, we performed functional analysis of lncRNA-targeted mRNAs and constructed an lncRNAmRNA network (Fig. 6; Additional file 9). The results showed that the mRNAs in the network (Fig. 6a) were mainly enriched in the 'oxidation-reduction process', 'oxidoreductase activity', 'hormone metabolic process', 'response to hormone stimulus', 'catalytic activity', 'cell wall organization' and 'external encapsulating structure' categories. We classified the target genes into four categories (cell wall polysaccharide metabolism, oxidationreduction processes, hormones and others) based on their functions and amounts.

Some lncRNAs specifically target functional mRNAs, and we can assume that the lncRNAs perform similar functions to their target mRNAs. For example, many of the target genes of XLOC_033910, XLOC_007053, and XLOC_008464 (Fig. 6b) are enriched in categories such as 'dioxygenase activity', 'oxidation-reduction process' and 'oxidoreductase activity', so we predicted their gene function as 'redox regulation'.

Some lncRNAs are targets of significantly differentially expressed mRNAs with various functions. For example, for XLOC_033910 (Fig. 6c), the target genes (Solyc06g060070.3,Solyc07g014670.3, Solyc05g055590.2, etc.) are enriched in the 'oxidoreductase activity' and 'dioxygenase activity' terms. XLOC_008464 also has other target genes, such as Solyc03g123550.1 ('response to hormone stimulus'), and Solyc11g005750.2 ('cell wall'). Previous studies [58-80] have shown that redox, hormone and cell wall terms are all very important factors that can influence fruit cracking, so we speculate that IncRNA XLOC_7053 may plays an important role in regulating tomato fruit cracking.

Liao's research strongly supported Ethylene-responsive factor 4 (ERF4) was associated with rind hardness and cracking resistance in watermelon fruits [88]. In our study, DEGs also included ethylene, as well as cell wall and redox related genes. Based on our research and previous research [67-69, 71-77], we mapped a "hormone- 


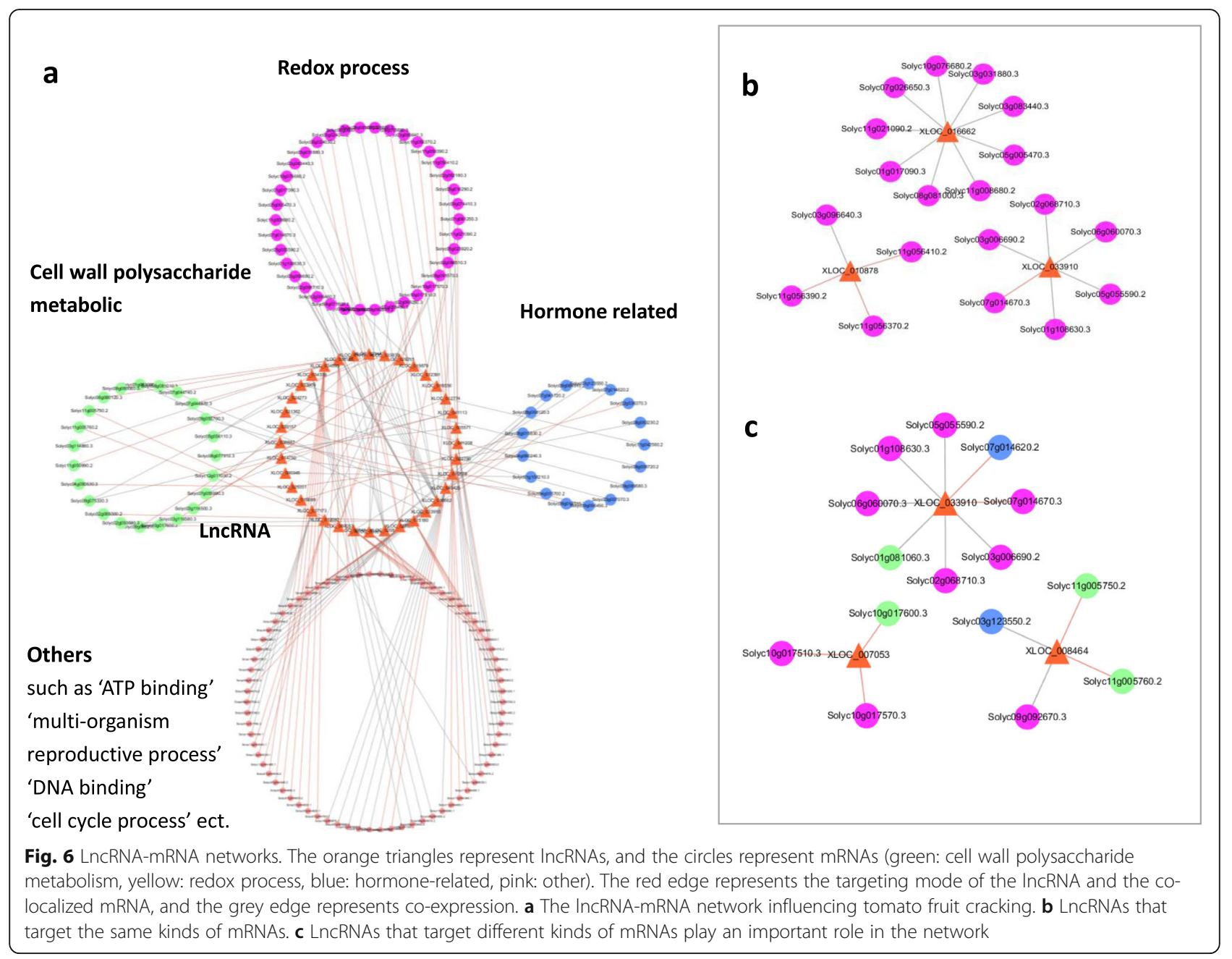

redox-cell wall" pathway diagram including lncRNA associated with fruit cracking.

\section{Conclusions}

In this study, the key genes involved in the response to tomato cracking were identified by high-throughput sequencing, which has important significance for guiding the selection of new tomato varieties. We have also established an lncRNA-mRNA (hormone-redox-cell wall) network to learn about the precise regulation of fruit cracking by lncRNAs. To the best of our knowledge, this is the first discovery of the lncRNA-mRNA network involved in tomato fruit cracking.

\section{Methods}

\section{Plant materials and sample collection}

RNA expression in $0 \mathrm{~h}, 8 \mathrm{~h}$ and $30 \mathrm{~h}$ irrigation-treated fruits from two contrasting tomato genotypes, 'LA1698' (cracking-resistant, CR) and 'LA2683' (cracking-susceptible, CS), was analysed by mRNA and lncRNA sequencing. 'LA2683' and 'LA1698' (Fig. 7) were both introduced by the Tomato Genetics Resource Centre (TGRC, University of California, Davis). The fruit cracking rates of 'LA2683' and 'LA1698' are 77.53 and 20.17\% (Additional file 10), respectively. Both lines were selected and self-pollinated for more than 6 generations. All the seedlings were grown in 72-plug trays on 18 March 2016. On 28 April 2016, they were transplanted to the same greenhouse of the Kunshan Yuye Leaf Vegetable Base $\left(31^{\circ} 95^{\prime} \mathrm{E}, 119^{\circ} 16^{\prime} \mathrm{N}\right)$, Suzhou, Jiangsu Province, China. The climate of this area belongs to the north subtropical south monsoon climate zone, with four distinct seasons and plenty of rainfall. The average annual temperature is $15.7^{\circ} \mathrm{C}$, and the annual average precipitation is $1094 \mathrm{~mm}$ according to China Weather Network (http://www.weather.com.cn/jiangsu). These two genotypes were planted side by side. Plant spacing followed a $30 \times 50 \times 100 \mathrm{~cm}$ pattern. Drip irrigation were adopted to guarantee the consistent of irrigation amount. Fertilization practices and pest control were those usually used by local growers. When fruits of the third cluster ripen, saturated irrigation based on previous 


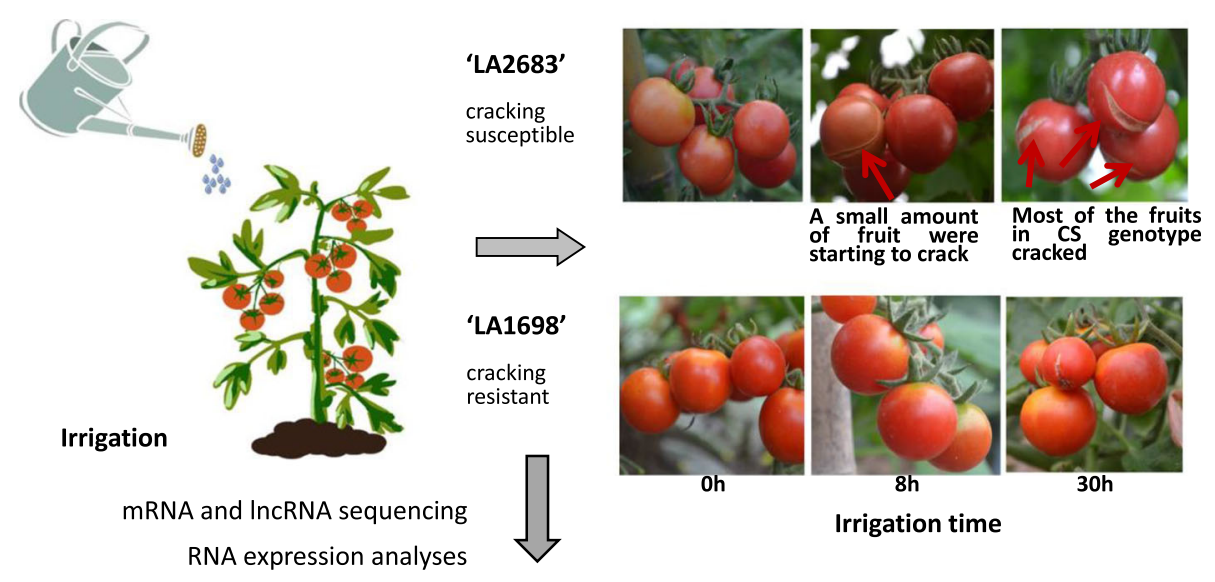

RNA-seq analysis

Differential expression analysis

Target gene prediction of IncRNA according to cis-regulation<smiles>C=CC=C</smiles>

\section{LncRNA and mRNA responsive network for water-induced cracking}

Fig. 7 Experimental flow chart

researches [2, 16, 31] with slightly modificationwas adopted to induce fruit cracking. Specifically, plants were firstly irrigated using flood irrigation for $2 \mathrm{~h}$. The field was essentially flooded with water which was allowed to totally soak into the soil. We then adopted drip irrigation to keep the soil saturated with water. After $0 \mathrm{~h}, 8 \mathrm{~h}$ and $30 \mathrm{~h}$ of irrigation treatment, for each genotype, treatment, one fruit were cut into four pieces from peduncle to blossom-end including exocarp and mesocarp without pulp. Each group has two repetitions. Samples of both genetypes were immediately frozen in liquid nitrogen and stored at $-80^{\circ} \mathrm{C}$. Sampling time is based on morphological observation. At $8 \mathrm{~h}$, cracked fruits began to appear in cracking susceptible tomato 'LA2683' but not in cracking resistant tomato 'LA1698'. At $30 \mathrm{~h}$, the fruits of 'LA2683' severely cracked and fruits of 'LA1698' slightly cracked.

\section{RNA-seq analysis}

Twelve fruit samples ( 2 genotypes, 3 time points, each with two replications) were collected and sequenced by Novogene, Beijing, China. RNA was extracted from the tomato pericarp, and qualified RNA samples were used to construct a cDNA library. Transcriptome sequencing was carried out on the Illumina HiSeq 2500 platform. Sequences showing low quality, linker contamination or a high unknown base $(\mathrm{N})$ content were filtered from the raw reads obtained after sequencing. The filtered highquality clean data were aligned to the ITAG4.0 reference genome using Hisat2 [89], and the transcriptome was assembled by using Cufflinks [90].

\section{Identification of mRNA and IncRNA}

The transcripts that could be compared to known transcript data were identified as annotated mRNAs.

Then, the transcripts were screened according to the following criteria: (1) exon number $\geq 2$ and (2) transcript length $\geq 200 \mathrm{bp}$. Additionally, (3) Transcripts that overlapped with the database annotation of the exon area according to Cuffcompare software were screened out. The lncRNAs overlapping with the exon region of a spliced transcript were included in the subsequent analysis. (4) The expression level of each transcript was calculated with Cuffquant, and transcripts with an FPKM $\geq 0.5$ were selected. (5) Two algorithms for evaluating protein-coding potential $(\mathrm{CPC} 2$ [91] and PFAM [92]) were used to predict the protein-coding potential of the remaining transcripts. Only when these two algorithms simultaneously indicated no protein-coding potential were the sequences considered to be predicted lncRNAs. Finally, the predicted lncRNAs were obtained. The transcripts showing the potential to encode proteins by "CPC2" and "PFAM" were identified as novel mRNAs (Fig. 8). 


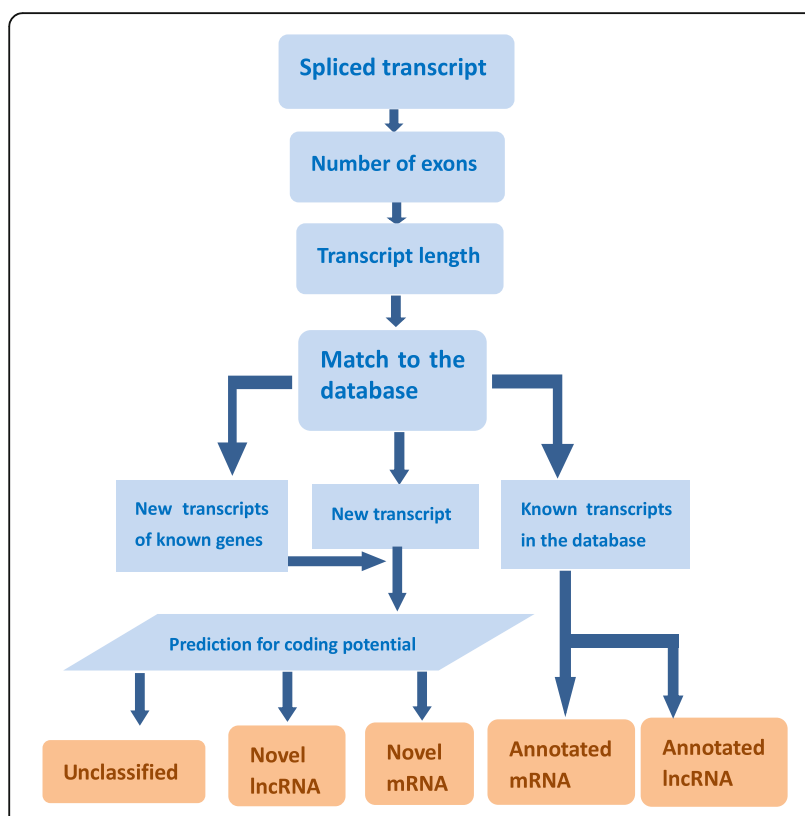

Fig. 8 Transcript screening process

\section{Analysis of mRNAs and IncRNAs}

The mRNA and lncRNA abundance of the unigenes was normalized via the fragments per kilobase of exon model per million mapped reads (FPKM) approach. The $\log 2$ fold changes between two samples were tested statistically to determine whether the expression of an individual gene was significantly altered. A $Q$-value $<0.05$ and $\mid \log 2$ fold-change $\mid>1$ was considered to indicate a differentially expressed gene (DEG). Analyses of mRNA and lncRNA expression trends in tomato fruit after irrigation were then carried out. To understand the function of differentially expressed mRNAs, these mRNAs were further subjected to GO (Gene Ontology) and KEGG (Kyoto Encyclopedia of Genes and Genomes) analysis by using GOseq [93] and KOBAS [94] software, respectively.

\section{Feature analysis of IncRNAs and identification of IncRNA- mRNA pairs}

Genomic characterization of the predicted lncRNAs was performed and compared with the mRNA results. The parameters for comparison to understand the genomic characteristics of the IncRNAs included the number of exons, ORF length, transcript nucleic acid length and sequence conservation between species.

LncRNAs mainly acts on their protein-coding target genes by cis-regulation or trans-regulation to achieve their regulatory functions. One of the functions of lncRNAs is cis-regulation of their neighbouring genes of the same allele; IncRNAs, which were located in less than $100 \mathrm{~kb}$ up/down stream of a gene, probably acted as cis-regulators. The up-stream lncRNAs having intersection of promoter or other cis-elements may regulate gene expression during or after transcription. The 3'UTR region or down-stream lncRNAs may perform other regulatory functions [95]. Another function of lncRNAs is the trans-regulation of co-expressed genes that are not adjacent to lncRNAs. For trans-regulation analysis, multiple repetitions are required for the result to be accurate and persuasive, samples with a value $<6$ are not recommended [96, 97]. So in this study, lncRNAs by cis-regulation were analyzed. LncRNA within $100 \mathrm{~kb}$ upstream and downstream of the mRNA was identified as the lncRNA-mRNA pair and the function of lncRNAs was predicted through functional enrichment analysis of the cis target gene.

\section{qRT-PCR verification}

Total RNA was extracted from tomato fruit by using the RNAprep Pure Plant Kit (Tiangen Biotech Co., Ltd. (Beijing, China)) following the manufacturer's instructions. cDNA was generated using $5 \mu \mathrm{l}$ of total RNA and abm's 5X All-In-One MasterMix. qRT-PCR was performed in a CFX 96 Touch RT-PCR detection system (Bio-Rad, USA) with abm's EvaGreen 2X qPCR MasterMix-Low ROX. Then, 9 DEGs were randomly selected from the DEGs to verify the RNA-seq results. Gene-specific primers were designed using Premier 5.0 [98] and actin as a reference gene [30]. The relative levels of gene expression were calculated using the $2^{-\Delta \Delta C T}$ method [99]. The sequences of the primers are listed in Additional file 11.

\section{Supplementary information}

Supplementary information accompanies this paper at https://doi.org/10 1186/s12870-020-02373-9.

Additional file 1: Table S1. LncRNAs in 12 tomato fruit libraries.

Additional file 2: Table S2. LncRNA-mRNA pairs were identified by cisregulation.

Additional file 3: Table S3. Number of differentially expressed mRNAs and IncRNAs in different libraries.

Additional file 4: Table S4. GO analysis of DEGs between groups. Additional file 5: Table S5. KEGG analysis of DEGs between groups. Additional file 6: Table S6. Key genes related to tomato fruit cracking. Additional file 7: Figure S1. Real-time PCR validation of highthroughput sequencing data. The $x$-axis represents the different time points of sampling, the left $y$-axis represents relative expression levels, and the right $y$-axis represents FPKM values. Blue bars represent data yielded by $q R T-P C R$, and red points represent data obtained by RNA sequencing. Different letters indicate significant differences $(P<0.05)$. (a) LA2683, (b) LA1698.

Additional file 8: Figure S2. The comparison of the relative expression measured by qRT-PCR and RNA-seq.

Additional file 9: Table S7. Data for the IncRNA-mRNA network. Additional file 10: Table S8. Statistics for tomato cracking rate of 'LA2683' and 'LA1698'. 
Additional file 11: Table S9. Detailed primer sequences for qRT-PCR

\section{Abbreviations}

CS: Cracking-susceptible; CR: Cracking-resistant; CS o h: Cracking-susceptible tomato fruit before irrigation $(0 \mathrm{~h})$; $\mathrm{CS} 8 \mathrm{~h}$ : Cracking-susceptible tomato fruit after $8 \mathrm{~h}$ of irrigation; CS $30 \mathrm{~h}$ : Cracking-susceptible tomato fruit after $30 \mathrm{~h}$ of irrigation; CR 0 h: Cracking-resistant tomato fruit before irrigation (0 h); CR 8 h: Cracking-resistant tomato fruit after 8 h of irrigation; CR 30 h: Crackingresistant tomato fruit after $30 \mathrm{~h}$ of irrigation; DEGs: Differentially expressed genes; GO: Gene Ontology; KEGG: Kyoto Encyclopedia of Genes and Genomes; qRT-PCR: Quantitative real-time PCR; FPKM: Expected number of fragments per kilobase of transcript sequence per millions base pairs sequenced

\section{Acknowledgements}

Not applicable.

\section{Authors' contributions}

JFL led and coordinated the project. XLZ and SMT collected the plant materials. YL and XLZ isolated the RNA. SMT and TYP conducted real-time quantitative PCR. XLZ, WZ and YQH conducted the bioinformatics analysis. $\mathrm{XLZ}$, SMT, and JFL wrote the paper. JFL is the corresponding author and is responsible for all contact and correspondence. All authors have read and approved the final manuscript.

\section{Funding}

The work was supported by grants from the National Natural Science Foundation of China (No. 31701924), the Fundamental Research Funds for the Central Universities (No. KJQN201814, KYZZ201909) and Priority Academic Program Development of Jiangsu Higher Education Institutions. The funders provided the financial but played no role in the study design, analysis of the data and in writing the manuscript.

\section{Availability of data and materials}

The datasets generated during and/or analysed during the current study are included in this published article (and its supplementary information files). All RNA sequencing data from this study are available in the NCBI sequence read archive (SRA) under accession numbers: SAMN14409497, SAMN14409498, SAMN14409499, SAMN14409500, SAMN14409501, SAMN14409502, SAMN14409503, SAMN14409504, SAMN14409505, SAMN14409506, SAMN14409507 and SAMN14409508 (https://www.ncbi.nlm. nih.gov/sra/PRJNA613785).

\section{Ethics approval and consent to participate} Not applicable.

\section{Consent for publication}

Not applicable.

\section{Competing interests}

The authors declare that there are no competing interests in the reported research.

\section{Author details}

${ }^{1}$ College of Horticulture, Nanjing Agricultural University, Weigang NO 1, Nanjing 210095, Xuanwu District, China. ${ }^{2}$ Key Laboratory of Horticultural Plant Biology and Germplasm Innovation in East China, Ministry of Agriculture, Nanjing 210095, China. ${ }^{3}$ Institute of Vegetables and Flowers, Chinese Academy of Agricultural Sciences, Zhongguancun South St, Beijing 10081, Haidian District, China. ${ }^{4}$ Institute of Vegetables, Xinjiang Academy of Agricultural Sciences, Nanchang Road 403, Urumchi 830091, Shayibake District, China.

Received: 27 August 2019 Accepted: 31 March 2020 Published online: 15 April 2020

\section{References}

1. Khadivikhub A, Zamani Z, Bouzari N. Evaluation of genetic diversity in some Iranian and foreign sweet cherry cultivars by using RAPD molecular markers and morphological traits. Hortic Environ Biotechnol. 2008;49(3):188-96.
2. Balbontín C. Ayala, et al. cracking in sweet cherries: a comprehensive review from a physiological molecular and genomic perspective. Chilean J Agric Res. 2013;73(1):66-72.

3. Mukhopadhyay A, Vij S, Tyagi AK. Overexpression of a zinc finger protein gene from rice confers tolerance to cold, dehydration, and salt stress in transgenic tobacco. Proc Natl Acad Sci U S A. 2004;101:6309-14.

4. Kang MY, Fokar M, Abdelmageed H, Allen RD. Arabidopsis SAP5 functions as a positive regulator of stress responses and exhibits E3 ubiquitin ligase activity. Plant Mol Biol. 2011;75:451-66.

5. Wu X, Shiroto Y, Kishitani S, Ito Y, Toriyama K. Enhanced heat and drought tolerance in transgenic rice seedlings overexpressing OsWRKY11 under the control of HSP101 promoter. Plant Cell Rep. 2009;28(1):21-30.

6. Sakuma Y, Maruyama K, Osakabe Y, et al. Functional analysis of an Arabidopsis transcription factor, DREB2A, involved in drought responsive geneexpression. Plant Cell. 2006;18(5):1292-309.

7. Yamaguchi-Shinozaki K, Shinozaki K. Organization of cis-acting regulatory elements in osmotic- and cold-stress-responsive promoters. Trends Plant Sci. 2005;10:88-94.

8. Liu JH, Peng T, Dai WS. Critical cis-acting elements and interacting transcription factors: key players associated with abiotic stress responses in plants. Plant Mol Biol Report. 2014;32:303-17..

9. Sawada E. Studies on the cracking of cherries. I. the cause of cracking. Agric Hortic. 1931;6:964-892

10. Khadivi-Khub A. Physiological and genetic factors influencing fruit cracking. Acta Physiol Plant. 2015;37:1718.

11. Cristián B, Héctor A, Bastías RM, et al. Cracking in sweet cherries: a comprehensive review from a physiological, molecular, and genomic perspective. Chilean J Agric Res. 2013;73(1):66-72.

12. Beyer M, Hahn R, Peschel S, Harz M, Knoche M. Analysing fruit shape in sweet cherry (Prunus avium L.). Sci Hortic. 2002;96:139-50.

13. Considine J, Brown K. Physical aspects of fruit growth. Theoretical analysis of distribution of surface growth forces in relation to cracking and splitting. Plant Physiol. 1981;68:371-6.

14. Cortes C, Ayuso MC, Palomares G, Cuartero J, Nuez F. Relationship between radial and concentric cracking of tomato fruit. Sci Hortic. 1983;21:323-8.

15. Domínquez E. Ferna'ndez MD, Herna'ndez JCL, et al. tomato fruit continues growing while ripening, affecting cuticle properties and cracking. Physiol Plant. 2012;146(4):473-86.

16. Emmons CLW, Scott JW. Environmental and physiological effects on cuticle cracking in tomato. J Am Soc Hortic Sci. 1997;122(6):797-801.

17. López-Casado G, Matas AJ, Domínguez E, Cuartero J, Heredia A. Biomechanics of isolated tomato (Solanum lycopersicuml.) fruit cuticles: the role of the cutin matrix and polysaccharides. J Exp Bot. 2007;58:3875-83.

18. Domínguez E, España L, López-Casado G, Cuartero J, Heredia A. Biomechanics of isolated tomato (Solanum lycopersicum) fruit cuticles during ripening: the role of flavonoids. Funct Plant Biol. 2009;36:613-20.

19. Ruiz-May E, Rose JKC. Progress toward the tomato fruit cell wall proteome. Funct Plant Biol. 2013;29:7.

20. Carpita NC, Campbell M, Tierney M. Pectin: cell biology and prospects for functional analysis. Plant Cell Walls. 2001;2:9-27.

21. Marin-Rodriguez MC. Pectate lyases, cell wall degradation and fruit softening. J Exp Bot. 2002;53(377):2115-9.

22. Geitmann PA. Pectin and the role of the physical properties of the cell wall in pollen tube growth of Solanum chacoense. Planta. 2005;220(4):582-92.

23. Cantu D, Vicente A, Greve $L$, et al. The intersection between cell wall disassembly, ripening, and fruit susceptibility to Botrytis cinerea. Proc Natl Acad Sci U S A. 2008;105(3):859-64.

24. Wang Y, Lu WJ, Li JG, Jiang Y. Differential expression of two expansion genes in developing fruit of cracking-susceptible and resistant litchi cultivars. J Am Soc Hortic Sci. 2006;131(1):118-21.

25. Kasai S, Hayama H, Kashimura Y, Kudo S, Osanai Y. Relationship between fruit cracking and expression of the expansin gene MdEXPA3 in 'Fuji' apples (Malus domesticaBorkh.). Sci Hortic. 2008;116(2):194-8.

26. Huang XM, Wang HC, Lu XJ, et al. Cell wall modifications in the pericarp of litchi (Litchi chinensis Sonn.) cultivars that differ in their resistance tocracking. J Hortic Sci Biotechnol. 2006:81(2):231-7.

27. Moctezuma E, Smith DL, Gross KC. Antisense suppression of a ß-galactosidase gene (TBG6) in tomato increases fruit cracking. J Exp Bot. 2003:54:2025-33.

28. Schuch W, Kanczler J, Robertson D, et al. Fruit quality characteristics of transgenic tomato fruit with altered polygalacturonase activity. Hortscience. 1991;26(12):1517-20 
29. Lu W, Wang $Y$, Jiang $Y$, et al. Differential expression of litchi XET genes in relation to fruit growth. Plant Physiol Bochemistry. 2006;44(11):707-13.

30. Jiang FL, Lopez A, Jeon S, et al. Disassembly of the fruit cell wall by the ripening-associated polygalacturonase and expansin influences tomato cracking. Horticulture Res. 2019;6:17.

31. Peet M. Fruit cracking in tomato. Hort Technol. 1992;2(2):216-23.

32. Cuartero J, Palomares $\mathrm{G}$, Balasch $\mathrm{S}$. Tomato fruit cracking under plastichouse and in the open air. II. General and specific combining abilities. BMC Infect Dis. 1981;15(1):1-13.

33. Yang ZE, Wu Z, Zhang C, Hu EM, Zhou R, Jiang FL. The composition of pericarp, cell aging, and changes in water absorption in two tomato genotypes: mechanism, factors, and potential role in fruit cracking. Acta Physiol Plant. 2016;38:215.

34. Birney E. Stamato yannopoulos JA, Dutta a, et al. Indentification and analysis of function elements in $1 \%$ of the human genome by the encode pilot project. Nature. 2007;447(7146):799-816

35. Derrien T, Johnson R, Bussotti G, et al. The GENCODE v7 catalog of human long noncoding RNAs: analysis of their gene structure, evolution, and expression. Genome Res. 2012;22(9):1775-89.

36. Ponting CP, Belgard TG. Transcribed dark matter: meaning or myth? Hum Mol Genet. 2010;19(R2):R162-8.

37. Huttenhofer A, Schattner P, Polacek N. Non-coding RNAs: hope or hype? Trends Genet. 2005;21(5):289-97.

38. Wang JQ, Zhang YJ, Ren JM, et al. Advances in research on biological functions and significance of long non-coding RNA. Life Sci. 2012;24(06):543-8.

39. Xin MM, Wang Y, Yao YY, et al. Identification and characterization of wheat long non-protein coding RNAs responsive to powdery mildew infection and heat stress by using microarray analysis and SBS sequencing. BMC Plant Biol. 2011;11:61.

40. Swiezewski S, Liu F, Magusin A, Dean C. Cold-induced silencing by long antisense transcripts of an Arabidopsis Polycomb target. Nature. 2009; 462(7274):799-802

41. Wang X, Ai G, Zhang C, et al. Expression and diversification analysis reveals transposable elements play important roles in the origin of Lycopersiconspecific IncRNAs in tomato. New Phytol. 2016;209(4):1442-55.

42. Cui J, Jiang N, Meng J, et al. LncRNA33732-respiratory burst oxidase module associated with WRKY1 in tomato- Phytophthora infestans interactions. Plant J. 2019:97(5):933-46.

43. Wang J, Yu W, Yang Y, et al. Genome-wide analysis of tomato long noncoding RNAs and identification as endogenous target mimic for microRNA in response to TYLCV infection. Sci Rep. 2015;5:16946.

44. Consortium TF, Carninci P, Kasukawa T, et al. The transcriptional landscape of the mammalian genome. Science. 2005;309(5740):1559-63.

45. Luo $\mathrm{H}$, Yang $\mathrm{H}$, Lin $\mathrm{Y}$, et al. LncRNA and mRNA profiling during activation of tilapia macrophages by HSP70 and Streptococcus agalactiae antigen. Oncotarget. 2017;8(58):98455-70.

46. Johnsson P, Lipovich L, Dan G, Morris KV. Evolutionary conservation of long non-coding RNAs; sequence, structure, function. Biochim Biophys Acta. 2014;1840:1063-71.

47. Park YB, Cosgrove DJ. A revised architecture of primary cell walls based on biomechanical changes induced by substrate-specific endoglucanases. Plant Physiol. 2012;158:1933-43.

48. Jan A, Yang GX, Nakamura $\mathrm{H}$, et al. Characterization of a xyloglucan endotransglucosylase gene that is up-regulated by gibberellin in rice. Plant Physiol. 2004;136(3):3670-81.

49. He H, Serraj R, Yang Q. Changes in OsXTH gene expression, ABA content, and peduncle elongation in rice subjected to drought at the reproductive stage. Acta Physiol Plant. 2009;31(4):749-56.

50. Tieman DM, Harriman RW, Ramamohan G, Handa AK. An antisense pectin methylesterase Fene alters pectin chemistry and soluble solids in tomato fruit. Plant Cell. 1992;4(6):667-79.

51. Quesada MA, Blanco-Portales R, Posé S, et al. Antisense down-regulation of the Fa PG1 gene reveals an unexpected central role for polygalacturonase in strawberry fruit softening. Plant Physiol. 2009;150:1022-32.

52. McQueen-Mason S, Cosgrove DJ. Disruption of hydrogen bonding between plant cell wall polymers by proteins that induce wall extension. Proc Natl Acad Sci U S A. 1994;91(14):6574-8.

53. Mo B, Bewley JD. The relationship between beta-mannosidase and endobeta-mannanase activities in tomato seeds during and following germination: a comparison of seed populations and individual seeds. J Exp Bot. 2003;54(392):2503-10.
54. Stålbrand H, Saloheimo A, Vehmaanperä J, et al. Cloning and expression in Saccharomyces cerevisiae of a Trichoderma reesei beta-mannanase gene containing a cellulose binding domain. Appl Environ Microbiol. 1995;61(3):1090-7.

55. Mohammad I, Sumit G, Meli VS, et al. Fruit ripening regulation of aMannosidase expression by the MADS box transcription factor RIPENING INHIBITOR and ethylene. Front Plant Sci. 2016;7:10.

56. Andrews J, Adams SR, Burton KS, Edmondson RN. Partial purification of tomato fruit peroxidase and its effect on mechanical properties of tomato fruit skin. J Exp Bot. 2002;53:2393-9.

57. Cordoba-Pedregosa C, Cordoba F, Villalba JM, Gonzaez-Reyes JA. Zonal changes in ascorbate and hydrogen peroxide contents, peroxidase, and ascorbate-related enzyme activities in onion roots. Plant Physiol. 2003;131:697-706.

58. Lin CC, Kao CH. Cell wall peroxidase against ferulic acid lignin, and $\mathrm{NaCl}-$ reddued root growth of rice seeding. J Plant Physiol. 2001;158:667-71.

59. Passardi F, Cosio C, Penel C, Dunand C. Peroxidases have more functions than a Swiss army knife. Plant Cell Rep. 2005;24:255-65.

60. Kampranis SC, Damianova R, Atallah M, et al. A novel plant glutathione Stransferase-peroxidase suppresses bax lethality in yeast. J Biol Chem. 2000; 275(38):29207-16

61. Marrs KA, Alfenito M, Lloyd AM, Walbot V. A glutathioneS-transferase involved in vacuolar transfer encoded bythe maize gene Bronze-2. Nature. 1995;375(6530):397-400

62. Bartling D, Radzio R, Steiner U, Weiler EW. A glutathione S-transferase with glutathione-peroxidase activity from Ara-bidopsis thaliana. Eur J Biochem. 1993;216(2):579-86.

63. Trainotti L, Zanin D, Casadoro G. A cell wall-oriented genomic approach reveals a new and unexpected complexity of the softening in peaches. J Exp Bot. 2003;54:1821-32.

64. Ruther J, Kleier S. Plant-plant signaling: ethylene synergizes volatile emission in Zea mays induced by exposure to (Z)-3-hexen-1-ol. J Chem Ecol. 2005;31: 2217-22.

65. Hossain MA, Kim S, Kim KH, Lee SJ, Lee H. Flavonoid compounds are enriched in lemon balm (Melissa officinalis) leaves by a high level of sucrose and confer increased antioxidant activity. Hortscience. 2009:44:1907-13.

66. Jeong SW, Das PK, Jeoung SC, et al. Ethylene suppression of sugar-induced anthocyanin pigmentation in Arabidopsis. Plant Physiol. 2010;154:1514-31.

67. Kalaitzis $\mathrm{P}$, Koehler $\mathrm{SM}$, Tucker ML. Cloning of a tomato polygalacturonase expressed in abscission. Plant Mol Biol. 1995;28:647-56.

68. Rose JK, Cosgrove DJ, Albersheim P, Darvill AG, Bennett AB. Detection of expansin proteins and activity duringtomato fruit ontogeny. Plant Physiol. 2000;123(4):1583-92.

69. Yoshida S, Tamaoki M, loki M, et al. Ethylene and salicylic acid control glutathione biosynthesis in ozone-exposed Arabidopsis thaliana. Physiol Plant. 2009;136(3):284-98.

70. Jablonkai I, Hatzios KK. In vitro conjugation of chloroacetanilide herbicides and atrazine with thiols and contribution of nonenzymatic conjugation to their glutathione mediated metabolism in corn. J Agric Food Chem. 1993; 41(10):1736-42.

71. Gao J, Zhang YX, Li ZG, Liu MC. Role of ethylene response factors (ERFs) in fruit ripening. Food Qual Saf. 2020;275:1-5.

72. Steffens B, Kovalev A, Gorb SN, Sauter M. Emerging roots Alter epidermal cell fate through mechanical and reactive oxygen species signaling. Plant Cell. 2012;24(8):3296-306.

73. Li JS, Dai XH, Zhao YD. A role for auxin response factor 19 in auxin and ethylene signaling in Arabidopsis. Plant Physiol. 2006;140(3):899-908.

74. Liszkay A. Production of reactive oxygen intermediates (O2 middle dot-, $\mathrm{H}_{2} \mathrm{O}_{2}$, and middle dotOH) by maize roots and their role in wall loosening and elongation growth. Plant Physiol. 2004;136(2):3114-23.

75. Wang BM, Ding GX, Wang XY, et al. Changes of histological structure and water potential of huping jujube fruit cracking. Sci Agric Sin. 2013;46(21):4558-68.

76. Ivanchenko MG, den Os D, Monshausen GB, Dubrovsky JG, Bednárová A, Krishnan $\mathrm{N}$. Auxin increases the hydrogen peroxide $\left(\mathrm{H}_{2} \mathrm{O}_{2}\right)$ concentration in tomato (Solanum lycopersicum) root tips while inhibiting root growth. Ann Bot. 2013:112(6):1107-16.

77. Rayle DL, Cleland R. Enhancement of wall loosening and elongation by acid solutions. Plant Physiol. 1970;46(2):250-3.

78. Nuruddin MM, Madramootoo CA, Dodds GT. Effects of water stress at different growth stages on greenhouse tomato yield and quality. Hort Science. 2003;38(7):1389-93.

79. Walter JM. Hereditary resistance to disease in tomato. Annu Rev Phytopathol. 1967;5:131-62. 
80. Cotner SD, Burns EE, Leeper PW. Pericarp anatomy of crackresistant and susceptible tomato fruits. J Am Soc Hortic Sci. 1969;94:136-7.

81. Capel C, Yuste-Lisbona FJ, López-Casado G, et al. Multi-environment QTL mapping reveals genetic architecture of fruit cracking in a tomato RIL Solanum lycopersicum $\times$ S. pimpinellifolium population. Tag.theoretical \& Applied Genetics. theoretische Und Angewandte Genetik. 2016;130(1):1-10.

82. Garcia-Luis A, Duarte AMM, Porras I, et al. Fruit splitting in "Nova" hybrid mandarin in relation to the anatomy of the fruit and fruit set treatments. Sci Hortic. 1994;57:215-31.

83. Wang SY, Camp MJ. Temperatures after bloom affect plant growth and fruit quality of strawberry. Sci Hortic. 2000;85:183-99.

84. Young HW. Inheritance of fruit cracking. Tomato Genet Coop. 1958;8:38.

85. Lieberman M, Kunishi A, Mapson LW, Wardale DA. Stimulation of ethylene production in apple tissue slices by methionine. Plant Physiol. 1966;41:7682.

86. Yang SF, Hoffman NE. Ethylene biosynthesis and its regulation in higher plants. Annu Rev Plant Physiol. 1984;35:155-89.

87. Wang KL-C, Li H, Ecker JR. Ethylene biosynthesis and signaling networks. Plant Cell. 2002;14:S131-51.

88. Liao NQ, Hu ZY, Li YY, et al. Ethylene-responsive factor 4 is associated with the desirable rind hardness trait conferring cracking resistance in fresh fruits of watermelon. Plant Biotechnol J. 2020:18(4):1066-77.

89. Kim D, Langmead B, Salzberg SL. HISAT: a fast spliced aligner with low memory requirements. Nat Methods. 2015;12(4):357-60.

90. Trapnell C, Williams BA, Pertea G, et al. Transcript assembly and quantification by RNA-Seq reveals unannotated transcripts and isoform switching during cell differentiation. Nat Biotechnol. 2010;28:511-5.

91. Kang YJ, Yang DC, Kong L, et al. CPC2: a fast and accurate coding potential calculator based on sequence intrinsic features. Nuc Acids Res. 2017;45(W1): $12-6$.

92. Finn RD, Tate J, Mistry J, et al. The Pfam protein families database. Nucleic Acids Res. 2008;32(1):D138.

93. Young MD, Wakefield MJ, Smyth GK. goseq: Gene Ontology testing for RNA-seq datasets; 2012.

94. Mao XZ, Cai T, Olyarchuk JG, Wei LP. Automated genome annotation and pathway identification using the KEGG Orthology (KO) as a controlled vocabulary. Bioinformatics. 2005:21:3787-93.

95. Guli S, Esteller M. Cis-acting noncoding RNAs: friends and foes. Nat Struct Mol Biol. 2012;19:1068-75.

96. Zhan SY, Dong Y, Zhao W, et al. Genome-wide identification and characterization of long non-coding RNAs in developmental skeletal muscle of fetal goat. BMC Genomics. 2016;17(1):666

97. Yang B, Xia ZA, Zhong B, et al. Distinct hippocampal expression profiles of long non-coding RNAs in an alzheimer's disease model. Mol Neurobiol. 2017;54(7):4833-46.

98. Lalitha S. Primer Premier 5. Biotech Softw Internet Rep. 2000;1 (6):270-2.

99. Livak KJ, Schmittgen TD. Analysis of relative gene expression data using real-time quantitative PCR and the 2(-Delta Delta $C(T))$ method. Methods. 2001;25(4):402-8.

\section{Publisher's Note}

Springer Nature remains neutral with regard to jurisdictional claims in published maps and institutional affiliations.

Ready to submit your research? Choose BMC and benefit from:

- fast, convenient online submission

- thorough peer review by experienced researchers in your field

- rapid publication on acceptance

- support for research data, including large and complex data types

- gold Open Access which fosters wider collaboration and increased citations

- maximum visibility for your research: over $100 \mathrm{M}$ website views per year

At $\mathrm{BMC}$, research is always in progress.

Learn more biomedcentral.com/submissions 